\title{
PHYSIOTHERAPY IN THE MANAGEMENT OF NON-COMMUNICABLE DisEASES: FACING THE CHALLENGE
}

\begin{abstract}
There is mounting evidence of the rising incidence and prevalence of non-communicable diseases in developing countries. Governments are facing serious challenges in health care due to the rising trends in non-communicable diseases as a result of demographic and epidemiological changes, as well as economic globalization. Cardiovascular disease, cancers, diabetes, respiratory disease, obesity and

\section{Frantz JM, PhD Physiotherapy}

${ }^{1}$ Department of Physiotherapy, University of the Western Cape, Bellville. other non-communicable conditions now account for 59 percent of the 56.5 million global deaths annually, and almost half, or 46 percent, of the global burden of disease. It is estimated that by 2020, non-communicable diseases will account for $60 \%$ of the global burden of disease. The burden of non-communicable diseases in sub-Saharan Africa is already substantial, and patients with these conditions make significant demands on health resources. How do these changes affect physiotherapists? This paper aims to highlight the need for physiotherapists to shift their focus from curative to preventive care in order to face the challenge of non-communicable diseases.
\end{abstract}

\section{KEY WORDS: PHYSIOTHERAPY, NON-COMMUNICABLE DISEASES, MANAGEMENT, PREVALENCE.}

\section{INTRODUCTION}

For centuries infectious diseases such as malaria, tuberculosis and cholera were the main causes of death worldwide and any advances against infection have been reversed by the rise of the HIV-related disorders (Alberti 2001). Against this gloomy background, noncommunicable diseases (e.g. cancer, cardiovascular disease, diabetes) are emerging as major problems as well. Disease rates from these non-communicable conditions are accelerating globally, advancing across regions and social classes. The majority of the chronic disease problems are currently also occurring in developing countries such as South Africa. The question that arises is whether physiotherapists are prepared to face this new challenge. This paper aims to identify the role of physiotherapy in the management of the non-communicable disease rise in South Africa.

\section{CORRESPONDENCE TO:}

JM Frantz

Private Bag x17

Bellville 7535

Tel: $\quad 27219592542(\mathrm{w})$

27219517706 (h)

Fax: 27219591217

Email: jfrantz@uwc.ac.za

\section{BURDEN OF NON-COMMUNICABLE DISEASES}

Governments are facing serious challenges in health care due to the rising trends in non-communicable diseases as a result of demographic and epidemiological changes, as well as economic globalization (Puska 2003). The World Health Report (2001) estimated that non-communicable diseases accounted for $60 \%$ of global mortality and $43 \%$ of the global burden of disease in 1999. The top worldwide "killer" diseases are cardiovascular disease, cancer, cerebrovascular disease, chronic obstructive pulmonary disease, diabetes, HIV/AIDS and malaria.

The World Health Report (2002) identifies five out of the ten leading global disease burden risk factors as high blood pressure, high cholesterol, obesity, physical inactivity and unhealthy diet. Together with alcohol and tobacco use, these preventable risks play a key role in the development of chronic diseases (WHO 2003). The burden of non-communicable diseases in sub-Saharan Africa is already substantial, and patients with these conditions make significant demands on health resources (Unwin et al 2001). In addition this burden of disease is likely to increase hugely over the coming decades. Epidemiological data from two
African countries indicate that the prevalence of non-communicable diseases such as diabetes and hypertension have increased tremendously over the past 5 years (Edwards et al 2000, Fourie and Steyn 1995). Based on the current trends, by the year 2020 non-communicable diseases are expected to account for $73 \%$ of deaths and $60 \%$ of the global burden of disease (World Health Report 2001). Risk factors for many of the non-communicable diseases are preventable and challenge health professionals to become involved in the monitoring of these emerging health issues in order to implement successful health promotion programs. Are we as physiotherapists adequately prepared to tackle the double burden of communicable and non-communicable diseases?

\section{MANAGING NON-COMMUNICABLE DISEASES IN SOUTH AFRICA}

In South Africa patterns of disease are exacerbated by an exploding epidemic of HIV/AIDS. This places a high demand on health services undergoing transformation in the face of shrinking budgets and other demands (Medical Research Council 2001). The consequences of these competing priorities are that there is little recognition of the magnitude of the burden of non-commu- 
nicable diseases in South Africa. The Medical Research Council report further states that in South Africa $56 \%$ of the population has at least one risk factor for non-communicable diseases, which includes hypertension and diabetes (Medical Research Council 2001). Clearly these risk factors require lifestyle changes and medical care to reduce the projected burden of disease.

There is strong scientific evidence suggesting that a change in dietary habits and physical activity can powerfully influence several of the risk factors in populations (Surgeon General Report 1996). Recognizing this, formulated a Global Strategy on Diet, Physical Activity and Health (WHO 2002a). This strategy will become the backbone for the World Health Organization in promoting global changes towards healthier diets and increased physical activity, to prevent chronic diseases and promote population health. As physical activity is a common denominator in many of the chronic diseases of lifestyle it has become evident that in promoting physical activity it can have enormous economic benefits in terms of health care costs, increased productivity, as well as healthier physical and social environments.

Within the current health care system in South Africa, which focuses on primary health care, there has been a shift from tertiary level hospitals to primary care hospitals. Within this primary health care package for South Africa, a set of norms have been set around chronic diseases (hypertension, type2 diabetes, stroke, etc.) which includes assessing patient satisfaction and quality of care regularly and evaluating community involvement as well as reducing the evidence of obesity within our communities and patient education (PHC 2000).

\section{THE ROLE OF PHYSIOTHERAPY}

How do these changes affect physiotherapists? Physiotherapy is both a curative and preventive discipline and forms an integral part of the health care system in South Africa. Physiotherapy employs a holistic approach to health care in which all the health needs of patients can be addressed. This means that the physiotherapist considers areas such as lifestyle, work and leisure and helps the patient to self-manage their condition. Swilling (1997) highlighted the need for physiotherapists to shift from the current form of professional service to involvement in primary health care, which embraces health promotion and disease prevention.

Thus how are physiotherapists dealing with this epidemic of non-communicable diseases? Van Rooijen and van der Spuy (2000) highlighted the need for physiotherapists to revisit their role of service delivery in South Africa. As physiotherapists our focus should be on prevention and not treatment. Included in prevention would be our focus on health promotion. Most non-communicable diseases are largely preventable by lifestyle changes including behavioral changes, accepting responsibility for your health and adopting a healthy lifestyle. Patients taking responsibility for their own health can influence the risk factors of non-communicable diseases (Eales and Stewart 2001). These authors further highlight that we need to realize that some of the barriers to the assumption of self-responsibility for health care in South Africa are factors such as lack of knowledge and cultural differences.

In addition, adopting a physically active lifestyle can also influence the risk factors of non-communicable diseases. The importance of exercise in managing diabetes is well documented (Van Rooijen et al 2002; Odebeyi and Ohwovoriole 2002). Physical activity is one of the cornerstones of a healthy lifestyle and one of the core skills used by physiotherapists is therapeutic exercise. Regular physical activity/exercise benefits many aspects of health. As public health professionals physiotherapists can make the public aware of modifying health behaviors to include physical activity (Stewart and Eales 2002). However, personal and environmental barriers should be taken into cognizance as these may contribute to non-adherence to physical activity promotion programs (Van Rooijen et al 2002).

\section{CONCLUSION}

There is a global shift of health care from curative to preventive management. The Ottawa Charter states that "health promotion includes building healthy public policy, creating supportive environments, strengthening community action, developing personal skills and reorienting health services" (WHO 2002b). In order to adequately address the challenging issues of non-communicable diseases that is pertinent to groups, communities and societies, we need to shift our paradigm from curative services to preventive services. By promoting lifestyle changes with an emphasis on physical activity, physiotherapists can make a major cost-effective contribution to the prevention, control and management of non-communicable diseases.

\section{REFERENCES}

Alberti G 2001. Noncommunicable diseases: tomorrow's pandemics. Editorial. Bulletin of the World Health Orainzation. 79: 907

American Heart Association 2002 Why Should I be physically active? American Heart Association. Dallas, Texas.

Baranowski T Bouchard C, Bar-Or O, Bricker T, Heath G, Kimm S, Malina R, Obarzanek E, Pate R, Strong W, Truman B, Washington R 1992 Assessment, prevalence and cardiovascular benefits of physical activity and fitness in youth. Medicine and Science in Sports and Exercise. 24: S237-S247.

Bar-Or O 1994 Childhood and adolescent physical activity and fitness and adult risk profile. In Bouchard C, Shepherd R and Stephens T (ed). Physical Activity, Fitness and Health. International Proceedings and Consensus Statement. P931-942.Champaign, Human Kinetics.

Centers for Disease Control and Prevention 2004 Physical Activity and Good Nutrition. Essential Elements to Prevent Chronic Diseases and Obesity. Atlanta.

Edwards R, Unwin N, Mugusi F 2000 Hypertension prevalence and care in an urban and rural area of Tanzania. Journal of Hypertension 18: 145-152.

Eales C, Stewart A 2001 Health and Responsibility: Self-efficacy, self-care and Self-responsibility. South African Journal of Physiotherapy 57: 20 - 25

Fourie J, Steyn K 1995 eds. Chronic Diseases of Lifestyle in South Africa. Medical Research Council of South Africa Technical Report. 
Limbert J, Crawford A, McCargar L 1994 Estimates of the prevalence of obesity in Canadian children. Obesity Research 2: 321-327.

Medical Research Council Report 2001 An Overview of Chronic Diseases of Lifestyle. Chronic Diseases of Lifestyle Unit. MRC.

Odebiyi D, Ohwovoriole A 2002 Exercise Tolerance in Type-2 Male Diabetics. South African Journal of Physiotherapy. 58: 17-20.

Primary Health Care Package for South Africa - A set of norms and standards 2000 http://www.doh.gov.za/docs/policy./norms/ part1z1.html

Puska P 2003 Curbing the Global Epidemic of Non-Communicable diseases. Business Briefing: Global Health Care 16-18.

Stephens T, Craig C 1990 The well-being of Canadians: Highlights of the 1988 Survey, Ottawa. Canadian Fitness and Lifestyle Research Institute.

Stewart A,Eales C 2002 Hypertension: Patient Adherence, Health Beliefs, Health Behaviour and Modification. South African Journal of Physiotherapy 58: 12-17.
Surgeon General Report 1996. Physical Activity and Health: A Report of the Surgeon General. US Department of Health and Human Services. Centers for Disease Control and Prevention.

Swilling P 1997 The future of Physiotherapy. PhysioForum 11: 18.

Troiano R, Flegal K, Kuczmarski R, Campbell S and Johnson J 1995 Overweight prevalence and trends for children and adolescents. Archives of Pediatric Adolescent Medicine 149: 1085-1091

Troiano R,Flegal K 1998 Overweight children and adolescents: description, epidemiology and demographics. Pediatrics 101: 497-504

Unwin N, Steel P, Rahid S, Mugusi F, Mbanya J, Kitange H, Hayes L, Edwards R, Aspray T and Alberti K 2001 Non communicable diseases in sub-Saharan Africa: where do they feature in the health research agenda? Bulletin of the World Health Organisation 79: 947-953.

Van Rooijen A. van der Spuy A 2000 The role of physiotherapists in a changing health care system. South African Journal of Physiotherapy 56: 3-8.
Van Rooijen A, Rheeder P, Eales C, Molatoli H 2002 Barriers to and Expectations of Performing Physical Activity in Female subjects with Type-2 Diabetes. South African Journal of Physiotherapy 58: 3-11.

World Health Organisation (2002a). Diet, Physical Activity and Health. 55th World Health Assembly. May 2002.

World Health Organisation (2002b). Ottawa Charter on Health Promotion. http://www. healthydocuments.info/public/doc10.html.

World Health Organization/7 (2003). Importance of NGO Input into Diet and Chronic Disease Strategy. WHO Press Releases 2003, Geneva.

World Health Organisation (2003). The report of the second meeting of the Global Forum on Noncommunicable Disease Prevention and Control. WHO, Geneva.

World Health Report (2001). Mental Health: New understanding, New hope. World Health Organisation, Geneva.

World Health Report (2002). Reducing Risk Promoting Healthy Life. World Health Organization. Geneva

\section{(Editorial continued from page 2)}

Provision of triple therapy to the public was obviously not a decision to be taken lightly. Poorly planned roll-out of ARVs could result in a major national resource - cheap, generic, effective ARVs - being squandered as compliance is not monitored and drug resistance builds up. It is sobering to think that the cure rate for tuberculosis is only $50-60 \%$ and this is a disease that can be cured with a relatively short period six months of drug therapy. The South African Government committed itself to providing ARV to 56000 of the estimated 500000 people living with HIV/AIDS in need of the drugs by the end of 2004. For many reasons the target was not met and only 27000 were receiving ARV treatment by this time. The issues are so complex, the magnitude of the problem is so great and the urgency is so pressing that all parties need to meet and plan a co-ordinated response to the epidemic.

South African physiotherapists have to respond to this disastrous epidemic and, as the magnitude of the problem is so much smaller in the North, we cannot be guided only by literature emanating from the established market economies. We must develop our own strategies, try them, test them and share the results. The people of South Africa need our unique understanding of functional deficits, our problem solving skills, our caring and our commitment to engage with this disease as never before.

Ass. Prof. J Jelsma (PhD)

Deputy Head of Division of Physiotherapy University of Cape Town

\section{REFERENCES}

Bradshaw D, Pettifor A, MacPhail, Dorrington R.2005 Trends in youth risk for HIV. Medical Research Council of South Africa

Decosas J 2003. HIV prevention and treatment in South Africa; affordable and desirable. The Lancet. 361: 1146-1147. http//:www. thelancet.com
Dorrington R, Bourne D, Bradshaw D, Laubscheer R, Timaeus I. 2001. The impact of HIV/AIDS on adult mortality in South Africa. pp. 1-56. Cape Town: Medical Research Council of South Africa.

Mars M 2004 South African Journal of Physiotherapy 60(4): 9-17

Shishana O \& Simbayi, I. 2002. Nelson Mandela/HSRC Study of HIV/AIDS: Human Science Research Centre of South Africa.

Venter L 2005 Firms fill antiretroviral gap in South Africa. The Lancet 365 (9466):12151216

UNAIDS/WHO epidemiological fact sheet on HIV/AIDS and Sexually Transmitted Infection, South Africa. 2004 Update. http://www,unaids.org Accessed on 19 May 2005 